\title{
KINEMATIC MODEL OF A CAR
}

\author{
Antoniya Raydovska ${ }^{1}$ \\ ${ }^{I}$ Department of Applied Mechanics, University of Chemical Technology and Metallurgy, Sofia, Bulgaria \\ e-mail:antonia_rajdovska@abv.bg
}

\begin{abstract}
The travelling comfort of the driver and the passengers is an indicator that assesses the quality of the car. The travelling comfort is graded according to the rates of the general vibrations experienced by the driver and the passengers in the car while travelling. The sources of vibrations in the car are the operating internal combustion engine and the roughness of the roadway on which the vehicle is moving. Free non-subsiding and subsiding vibrations and forced vibrations of the car are examined with mathematical models. In this article a kinematic model of a car has been synthesized. The car is presented as a mechanical system composed of perfectly rigid bodies. The bodies are interconnected with holonomic constraints and elastic-damping elements. Equations of the angular velocities of the bodies of the mechanical system and of the linear velocity rates of the centres of gravity of these bodies have been derived.
\end{abstract}

Keywords: Kinematic model, Linear velocity, Angular velocity, A car

The following symbols have been used in the article:

$\mathbf{R}$ - Radius vector in the fixed coordinate system;

$\mathbf{r}$ - Radius vector in the local coordinate system;

$\mathrm{O}$ - Centre of the coordinate system;

C-Centre of gravity;

A - Transformation matrix;

1- Length;

V - Linear velocity vector;

W - Angular velocity vector;

Oxyz - Cartesian coordinate system;

$\mathrm{x}, \mathrm{y}, \mathrm{z}$ - Axes of a Cartesian coordinate system, movement;

$\Phi$ - Angle of rotation;

$\theta$ - Angle of small rotation.

\section{Indices:}

Bottom - a coordinate system, in which the body is designed:

$i$ - Number of a body from the mechanical system;

$t$ - Translation;

$u$ - Rotation;

0 - Fixed coordinate system.

Upper - a coordinate system, in which the body is designed: $\mathrm{T}$-Transpose;

$i$ - Number of a body from the mechanical system.

\section{Abbreviations:}

Local coordinate system (LCS);

Starting coordinate system (SCS).

\section{INTRODUCTION}

Basic requirement regarding the travelling by car is the safety of the people travelling in it and of the other participants in the car traffic. The car steadiness and control as well as the travelling comfort of the passengers depend on the car vibrations. The different human body parts have different rates of own frequencies [5]. It is known that if the frequencies of the forced vibrations and the own frequencies of the driver's eyes are equal, there's discomfort regarding the driver's eyesight. Because of this, research into car vibrations is remarkable. There are limit vibration rate to estimate the travelling comfort of the passengers in a car. The limit vibration rates are set with national and international standards. These rates are set for the three axes of a Descartes coordinate system. Because of this the research of the car should be made according to these three axes $[1,2]$.

\section{KINEMATIC MODEL}

Kinematic models of multibody mechanical systems with a different number of degrees of freedom are investigated in $[2,3,4,6,7,8,9,10,11]$. A car with independent suspension of the front and the back wheels is presented in [6]. The car is presented as a multibody mechanical system, composed of 15 perfect rigid bodies. The kinematic model has 39 degrees of freedom. In the article presented the research is into a car with an internal combustion engine (ICE), independent suspension of the front wheels and dependent suspension of the back wheels.

The internal combustion engine is a source of forced vibrations in the car. The exhaust pipe of the car is installed to the ICE. The tailpipe is also a source of forced vibrations. Because of this the exhaust pipe and the ICE are included in the kinematic model.

The roadway roughness on which the car moves is a source of forced vibrations in the car. These vibrations are reduced by the elements of the car suspension. Because of this, the car suspension elements are included in the kinematic model. The kinematic model includes also the driver and the 
passengers in the car so as to estimate the vibrations they feel.

In the kinematic model of the car the following car parts are included (fig.1): 1- coupé; 2 - ICE; 3, 5 - suspension arm of a front wheel, respectively left and right; 4, 6 - steering knuckle with a rim and tire, respectively in left and right wheel, 7 - back axle with rims and tires; 8, 9, 10, 11 passengers; 12 - tailpipe. Here is the assumption that these bodies are perfectly rigid. The bodies are interconnected with holonomic and fixed constraints. Defined this way, the kinematic model, composed of 12 perfectly rigid bodies, has 31 degrees of freedom. The summarized coordinates vector is from the type:

$$
\mathbf{q}=\left[\begin{array}{llll}
\mathrm{q}_{1}^{\mathrm{T}} & \mathrm{q}_{2}^{\mathrm{T}} & \cdots & \mathrm{q}_{12}^{\mathrm{T}}
\end{array}\right]_{31 \times 1}^{\mathrm{T}}
$$

A Cartesian coordinate system is fixed to each body of the mechanical system. It moves together with the body and is called local coordinate system (LCS). Every LCS receives the number of the body. The centre of every LCS is located as follows

- The gravity centre of each of the bodies $1,2,8,9$, 10, 11, 12; List Item - 2

- $\quad$ on the axis of symmetry of the cylindrical joint, formed among the bodies 3, 5, 7, on the one hand, and the car coupé, on the other hand

- $\quad$ in the centre of the spherical joint, formed by the body couples 3 and 4, 5 and 6 .

The local coordinate systems move according to a nonmoving coordinate system whose number is 0 .

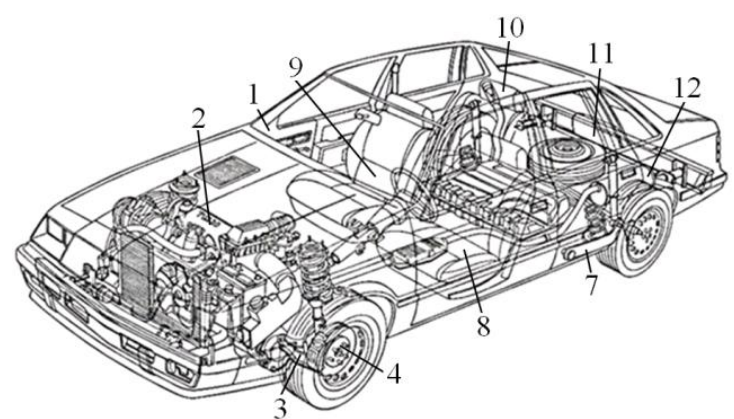

Fig -1: Scheme of the car bodies involved in the kinematic model

Bodies 1, 2 and 12 are fixed onto elastic-damping elements which deform along the three axis of a Cartesian coordinate system. These bodies make translational and rotational movements along the axis of a Cartesian coordinate system. Each of the bodies 1, 2, 12 has six degrees of freedom [1, 4]. The vector of the summarized coordinates of each of these bodies is from the type:

$$
\mathbf{q}_{i}=\left[\begin{array}{llllll}
x_{i} & y_{i} & z_{i} & \theta_{X_{i}} & \theta_{Y_{i}} & \theta_{Z_{i}}
\end{array}\right]_{(6 \times 1)}^{T}, \quad i=1,2,12
$$

The body couples 1 and 3, and 1 and 5 form spinning pairs. Because of this, the bodies 3 and 5 have one degree of freedom - rotation around an Ox axis of the corresponding local coordinate system. The vector of the summarized coordinates of body 3 and body 5 is from the type:

$$
\mathbf{q}_{\mathrm{i}}=\left[\Phi_{1 \mathrm{i}}\right], \mathrm{i}=3,5
$$

Where:

$\Phi_{1 \mathrm{i}}=\Phi_{\mathrm{Xi}}+\theta_{\mathrm{Xi}}$

As each one of the body couples 3 and 4 , and 5 and 6 , form a spherical pair, each one of the bodies 4 and 6 has three degrees of freedom - rotation around the axes of the corresponding local coordinate system. The vector of the summarized coordinates of body 4 and body 6 is from the type:

$$
\mathbf{q}_{\mathrm{i}}=\left[\begin{array}{lll}
\Phi_{1_{\mathrm{i}}} & \Phi_{2_{\mathrm{i}}} & \Phi_{3_{\mathrm{i}}}
\end{array}\right]^{\mathrm{T}}, \quad \mathrm{i}=4,6
$$

Where:

$$
\begin{aligned}
& \Phi_{1 \mathrm{i}}=\Phi_{\mathrm{Xi}}+\theta_{\mathrm{Xi}}, \\
& \Phi_{2 \mathrm{i}}=\Phi_{\mathrm{Yi}}+\theta_{\mathrm{Yi}}, \\
& \Phi_{3 \mathrm{i}}=\Phi_{\mathrm{Xi}}+\theta_{\mathrm{Xi}} .
\end{aligned}
$$

Body 7 and the car frame form a spinning pair. Because of this, body 7 has one degree of freedom - rotation around an $\mathrm{O}_{7} \mathrm{y}_{7}$ axis. The vector of the summarized coordinate is from the type:

$$
\mathbf{q}_{7}=\left[\Phi_{27}\right]
$$

Where:

$$
\Phi_{27}=\Phi_{\mathrm{Y} 7}+\theta_{\mathrm{Y} 7}
$$

It is accepted that each body with number from 8 to 11 makes a translational movement along an $\mathrm{Oz}$ axis of the corresponding local coordinate system. Each one of these bodies has one degree of freedom. The vector of the summarized coordinate of each body is from the type:

$$
\mathbf{q}_{i}=\left[z_{i}\right], \quad i=8,9, \ldots, 11
$$

\section{TRANSFORMATION MATRIX}

The bodies included in the car kinematic model are interconnected in kinematic chains. The transformation matrix of the centre $\mathrm{O}_{\mathrm{i}}$ of the $\mathrm{i}$-th local coordinate system of the $\mathrm{i}$-th body from the kinematic chain to the non-moving coordinate system is written with the equation:

$$
\mathbf{A}_{\mathrm{i}}^{0}=\mathbf{A}_{1}^{0} \cdot \mathbf{A}_{2}^{1} \cdot \mathbf{A}_{3}^{2} \ldots \mathbf{A}_{\mathrm{i}}^{\mathrm{i}-1}
$$

Where:

$$
\mathbf{A}_{\mathrm{i}}^{\mathrm{i}-1}=\mathbf{A} \mathrm{t}_{\mathrm{i}}^{\mathrm{i}-1} \cdot \mathbf{A} \mathrm{u}_{\mathrm{i}}^{\mathrm{i}},
$$




$$
\begin{aligned}
& \mathbf{A t}_{\mathrm{i}}^{\mathrm{i}-1}=\left[\begin{array}{cccc}
1 & 0 & 0 & 1_{\mathrm{O}}^{\mathrm{i}-1} \\
0 & 1 & 0 & 1_{\mathrm{O}_{\mathrm{Y}_{\mathrm{i}}}}^{\mathrm{i}-1} \\
0 & 0 & 1 & 1_{\mathrm{O}_{Z_{\mathrm{i}}}}^{\mathrm{i}-1} \\
0 & 0 & 0 & 1
\end{array}\right], \\
& \mathbf{A} u_{\mathrm{i}}^{\mathrm{i}}=\mathbf{A} \mathrm{u}_{\mathrm{Xi}} \cdot \mathbf{A} \mathrm{u}_{\mathrm{Yi}} \cdot \mathbf{A} \mathrm{u}_{\mathrm{Zi}} \text {, } \\
& \mathbf{A} u_{X_{i}}=\left[\begin{array}{cccc}
1 & 0 & 0 & 0 \\
0 & \cos \theta_{X_{i}} & -\sin \theta_{X_{i}} & 0 \\
0 & \sin \theta_{X_{i}} & \cos \theta_{X_{i}} & 0 \\
0 & 0 & 0 & 1
\end{array}\right], \\
& \mathbf{A} u_{Y_{i}}=\left[\begin{array}{cccc}
\cos \theta_{Y_{i}} & 0 & \sin \theta_{Y_{i}} & 0 \\
0 & 1 & 0 & 0 \\
-\sin \theta_{Y_{i}} & 0 & \cos \theta_{Y_{i}} & 0 \\
0 & 0 & 0 & 1
\end{array}\right], \\
& \mathbf{A} \mathrm{u}_{\mathrm{Zi}}=\left[\begin{array}{cccc}
\cos \theta_{\mathrm{Z}_{\mathrm{i}}} & -\sin \theta_{\mathrm{z}_{\mathrm{i}}} & 0 & 0 \\
\sin \theta_{\mathrm{Z}_{\mathrm{i}}} & \cos \theta_{\mathrm{z}_{\mathrm{i}}} & 0 & 0 \\
0 & 0 & 1 & 0 \\
0 & 0 & 0 & 1
\end{array}\right] \text {. }
\end{aligned}
$$

The transformational matrixes of the points $\mathrm{O}_{\mathrm{i}}(\mathrm{i}=1,2, \ldots$, 12) of each body from the kinematic model are the following:

\subsection{Body 1}

The location scheme of LCS 1, LCS 2, LCS 12 in SCS is presented in fig. 2.

The transformational matrix of point $\mathrm{O} 1$ is from the type:

$$
\mathbf{A}_{1}^{0}=\mathbf{A} \mathrm{t}_{1}^{0} \cdot \mathbf{A} \mathrm{u}_{1}^{1}=\mathbf{A} \mathrm{u}_{\mathrm{X} 1} \cdot \mathbf{A} \mathrm{u}_{\mathrm{Y} 1} \cdot \mathbf{A} \mathrm{u}_{\mathrm{Z} 1}
$$

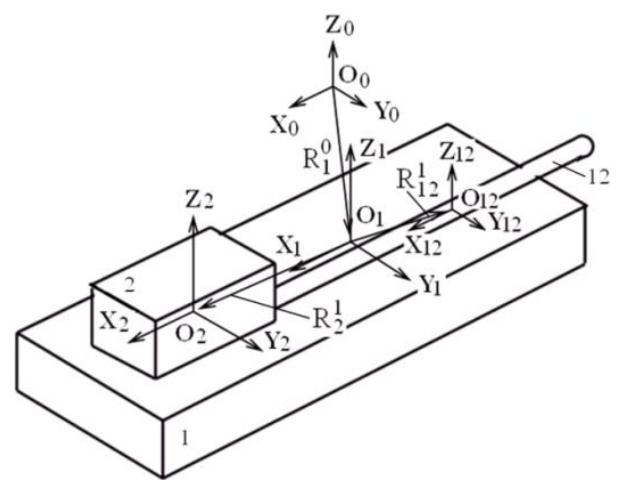

Fig -2: Scheme of the position of LCS 1, LCS 2, LCS 3 and FCS

\subsection{Bodies 2 and 12}

The transformational matrixes of the points are from the type:

$$
\mathbf{A}_{\mathrm{i}}^{0}=\mathbf{A}_{1}^{0} \cdot \mathbf{A}_{\mathrm{i}}^{1}, \mathrm{i}=2,12,
$$

Where:

$$
\begin{aligned}
& \mathbf{A}_{\mathrm{i}}^{1}=\mathbf{A} \mathbf{t}_{\mathrm{i}}^{1} \cdot \mathbf{A} \mathbf{u}_{\mathrm{i}}^{\mathrm{i}}, \\
& \mathbf{A} \mathbf{u}_{\mathrm{i}}^{\mathrm{i}}=\mathbf{A} \mathbf{A u}_{\mathrm{Xi}} \cdot \mathbf{A} \mathbf{u}_{\mathrm{Yi}} \cdot \mathbf{A} \mathbf{u}_{\mathrm{Zi}}
\end{aligned}
$$

\subsection{Bodies 3 and 5}

The transformational matrixes of the points are from the type:

$$
\mathbf{A}_{\mathrm{i}}^{0}=\mathbf{A}_{1}^{0} \cdot \mathbf{A}_{\mathrm{i}}^{1}, \quad \mathrm{i}=3,5,
$$

Where:

$$
\begin{aligned}
& \mathbf{A}_{\mathrm{i}}^{1}=\mathbf{A} \mathbf{t}_{\mathrm{i}}^{1} \cdot \mathbf{A} \mathbf{u}_{\mathrm{i}}^{\mathrm{i}}, \\
& \mathbf{A} \mathbf{u}_{\mathrm{i}}^{\mathrm{i}}=\mathbf{A} \mathbf{u}_{\mathrm{Xi}}
\end{aligned}
$$

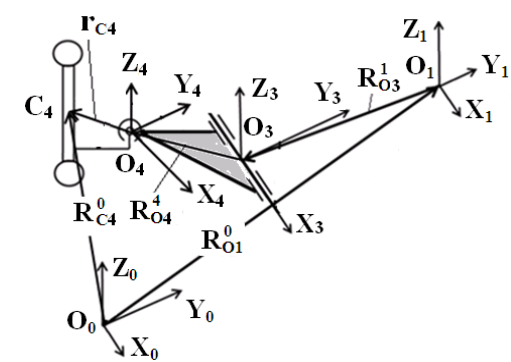

Fig -3: Location scheme of LCS 1, LCS 3, LCS 4 и SCS

\subsection{Bodies 4 and 6}

The transformational matrixes of the points are from the type:

$$
\mathbf{A}_{\mathrm{i}}^{0}=\mathbf{A}_{1}^{0} \cdot \mathbf{A}_{\mathrm{i}}^{1}, \mathrm{i}=4,6,
$$

Where:

$$
\begin{aligned}
& \mathbf{A}_{\mathrm{i}}^{1}=\mathbf{A} \mathbf{t}_{\mathrm{i}}^{1} \cdot \mathbf{A} \mathbf{u}_{\mathrm{i}}^{\mathrm{i}}, \\
& \mathbf{A} \mathbf{u}_{\mathrm{i}}^{\mathrm{i}}=\mathbf{A} \mathbf{A u}_{\mathrm{Xi}} \cdot \mathbf{A} \mathbf{u}_{\mathrm{Yi}} \cdot \mathbf{A} \mathbf{u}_{\mathrm{Zi}}
\end{aligned}
$$

\subsection{Body 7}

The transformational matrix of the point $\mathrm{O} 7$ is from the type:

$$
\mathbf{A}_{7}^{0}=\mathbf{A}_{1}^{0} \cdot \mathbf{A}_{7}^{1},
$$

Where:

$$
\mathbf{A}_{7}^{1}=\mathbf{A} \mathbf{t}_{7}^{1} \cdot \mathbf{A u}_{7}^{7} \text {, }
$$




$$
\mathbf{A u}_{7}^{7}=\mathbf{A} \mathbf{u}_{\mathrm{Y} 7}
$$

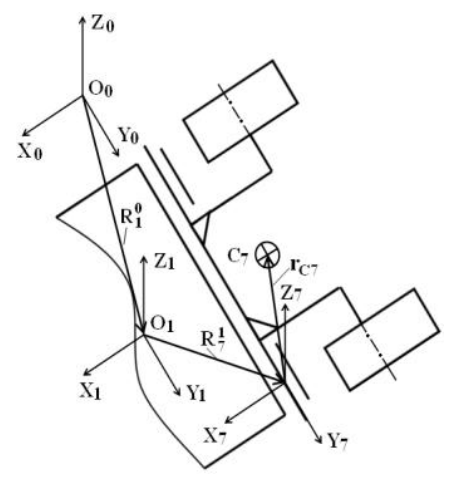

Fig -4: Location scheme of LCS 1, LCS 7 и SCS

\subsection{Bodies 8, 9, 10, 11}

The transformational matrixes of the points are from the type:

$$
\mathbf{A}_{\mathrm{i}}^{0}=\mathbf{A}_{1}^{0} \cdot \mathbf{A}_{\mathrm{i}}^{1}, \quad \mathrm{i}=8,9,10,11
$$

Where:

$$
\mathbf{A}_{\mathrm{i}}^{1}=\mathbf{A} \mathbf{t}_{\mathrm{i}}^{1} \cdot \mathbf{A u}_{\mathrm{i}}^{1^{*}} \cdot \mathbf{A} \mathrm{t}_{\mathrm{i}}^{\mathrm{i}}
$$

$$
\mathbf{A u}_{\mathrm{i}}^{1^{1^{*}}}=\left[\begin{array}{ccc}
0 & 0 & \alpha_{\mathrm{Yi}} \\
0 & 0 & 0 \\
-\alpha_{\mathrm{Yi}} & 0 & 0
\end{array}\right]
$$

$$
\mathbf{A t}_{\mathrm{i}}^{\mathrm{i}}=\left[\begin{array}{lll}
0 & 0 & \mathrm{z}_{\mathrm{i}}
\end{array}\right]^{\mathrm{T}}
$$

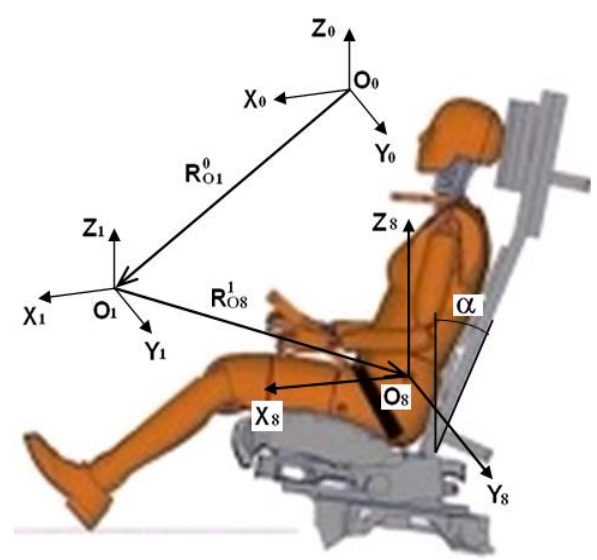

Fig -5: Location scheme of LCS 1, LCS 8 и SCS

4. RADIUS-VECTOR OF THE CENTRE OF GRAVITY OF A BODY FROM THE KINEMATIC MODEL, DESIGNED IN THE STARTING COORDINATE SYSTEM
The radius-vector of the gravity centre $C_{i}, i=1,2, \ldots, 12$ of the $\mathrm{i}$-th body from the kinematic model in the non-moving coordinate system is from the type:

$$
\mathbf{R}_{\mathrm{Ci}}^{0}=\mathbf{A}_{\mathrm{i}}^{0} \cdot \mathbf{r}_{\mathrm{Ci}}^{0}, \quad \mathrm{i}=1,2, \ldots, 12
$$

Where:

$$
\mathbf{r}_{\mathrm{Ci}}^{\mathrm{i}}=\left[\begin{array}{llll}
\mathrm{l}_{\mathrm{Ci} X i}, & 1_{\mathrm{Ci} Y \mathrm{i}}, & 1_{\mathrm{Ci} Z}, & 1
\end{array}\right]^{\mathrm{T}}
$$

is the radius-vector of the gravity centre of the i-th body from the mechanical system in the local CS [1]:

\section{VECTOR OF THE ABSOLUTE ANGULAR VELOCITY OF A BODY FROM THE MECHANICAL SYSTEM}

The vector of the absolute angular velocity of the i-th body, designed onto the axes of the i-th local CS, is calculated with the equation:

$$
\begin{aligned}
& \mathbf{W}_{\mathrm{i}}^{\mathrm{i}}=\mathbf{W}_{\mathrm{zi}}^{\mathrm{i}}+\mathrm{Au}{ }_{\mathrm{zi}}{ }^{\mathrm{T}} \cdot \mathbf{W}_{\mathrm{yi}}^{\mathrm{i}}+\mathbf{A} \mathbf{u}_{\mathrm{zi}}{ }^{\mathrm{T}} \cdot \mathbf{A} \mathbf{u}_{\mathrm{yi}}{ }^{\mathrm{T}} \cdot \mathbf{W}_{\mathrm{xi}}^{\mathrm{i}}, \\
& \mathrm{i}=1,2, \ldots, 12
\end{aligned}
$$

Some of the bodies from the kinematic model are interconnected consecutively. The absolute angular velocity vector of the i-th body from the consecutively connected bodies of the kinematic model is written with the equation:

$$
\begin{aligned}
& \mathbf{W}_{\mathrm{i}}^{\mathrm{i}}=\mathbf{W}_{\mathrm{z}}^{\mathrm{i}}+\mathrm{Au}_{\mathrm{zi}}{ }^{\mathrm{T}} \cdot \mathbf{W}_{\mathrm{yi}}^{\mathrm{i}}+\mathrm{Au}_{\mathrm{zi}}{ }^{\mathrm{T}} \cdot \mathrm{Au}_{\mathrm{yi}}{ }^{\mathrm{T}} \cdot \mathbf{W}_{\mathrm{xi}}^{\mathrm{i}}+ \\
& +\mathrm{Au}_{\mathrm{z}}{ }^{\mathrm{T}} \cdot \mathrm{Au}_{\mathrm{yi}}{ }^{\mathrm{T}} \cdot \mathrm{Au}_{\mathrm{xi}}{ }^{\mathrm{T}} \cdot \mathbf{W}_{\mathrm{i}-1}^{\mathrm{i}-1}+ \\
& +\mathrm{Au}_{\mathrm{zi}}{ }^{\mathrm{T}} \cdot \mathrm{Au}_{\mathrm{yi}}{ }^{\mathrm{T}} \cdot \mathrm{u}_{\mathrm{xi}}{ }^{\mathrm{T}} \cdot \mathrm{Au}_{\mathrm{z}-1}{ }^{\mathrm{T}} \cdot \mathrm{Au}_{\mathrm{yi}-1}{ }^{\mathrm{T}} \cdot \mathrm{Au}_{\mathrm{xi}-1}{ }^{\mathrm{T}} \cdot \mathbf{W}_{\mathrm{i}-2}^{\mathrm{i}-2}+\ldots, \\
& \mathrm{i}=1,2, \ldots, 12
\end{aligned}
$$

For every body of the kinematic model the absolute angular velocity vector of the $\mathrm{i}$-th body is from the type:

Bodies 1, 2, 12

$$
\begin{aligned}
& \mathbf{W}_{i}^{\mathrm{i}}=\mathbf{A} \mathbf{u}_{\mathrm{Zi}}^{\mathrm{T}} \cdot \mathbf{A} \mathbf{u}_{\mathrm{Yi}}^{\mathrm{T}} \cdot \mathbf{W}_{\mathrm{Xi}}^{\mathrm{i}}+\mathbf{A} \mathbf{u}_{\mathrm{Zi}}^{\mathrm{T}} \cdot \mathbf{W}_{\mathrm{Yi}}^{\mathrm{i}}+\mathbf{W}_{\mathrm{Zi}}^{\mathrm{i}}, \\
& \mathrm{i}=1,2,12
\end{aligned}
$$

Bodies 3 and 5

$$
\mathbf{W}_{\mathrm{i}}^{\mathrm{i}}=\mathbf{A} \mathbf{u}_{\mathrm{Xi}}^{\mathrm{T}} \cdot \mathbf{W}_{1}^{1}+\mathbf{W}_{\mathrm{Xi}}^{\mathrm{i}}, \mathrm{i}=3,5
$$

\section{Bodies 4 and 6}

$$
\begin{aligned}
& \mathbf{W}_{\mathrm{i}}^{\mathrm{i}}=\mathbf{A} \mathbf{u}_{\mathrm{Zi}}^{\mathrm{T}} \cdot \mathbf{A} \mathbf{u}_{\mathrm{Yi}}^{\mathrm{T}} \cdot \mathbf{A} \mathbf{u}_{\mathrm{Xi}}^{\mathrm{T}} \cdot \mathbf{A} \mathbf{u}_{\mathrm{Xi}-1}^{\mathrm{T}} \cdot \mathbf{W}_{1}^{1}+ \\
& +\mathbf{A} \mathbf{u}_{\mathrm{Zi}}^{\mathrm{T}} \cdot \mathbf{A} \mathbf{u}_{\mathrm{Yi}}^{\mathrm{T}} \cdot \mathbf{A} \mathbf{u}_{\mathrm{Xi}}^{\mathrm{T}} \cdot \mathbf{W}_{\mathrm{i}-1}^{\mathrm{i}-1}+ \\
& +\mathbf{A} \mathbf{u}_{\mathrm{Zi}}^{\mathrm{T}} \cdot \mathbf{A} \mathbf{u}_{\mathrm{Yi}}^{\mathrm{T}} \cdot \mathbf{W}_{\mathrm{Xi}}^{\mathrm{i}}+\mathbf{A} \mathbf{u}_{\mathrm{Zi}}^{\mathrm{T}} \cdot \mathbf{W}_{\mathrm{Yi}}^{\mathrm{i}}+\mathbf{W}_{\mathrm{Zi}}^{\mathrm{i}} \\
& \mathbf{i}=4,6
\end{aligned}
$$

\section{Body 7}


$\mathbf{W}_{7}^{7}=\mathbf{A} \mathbf{u}_{\mathrm{Y} 7}^{\mathrm{T}} \cdot \mathbf{W}_{1}^{1}+\mathbf{W}_{\mathrm{Y} 7}^{7}$

Bodies 8, 9,..., 11

$$
\mathbf{W}_{i}^{\mathrm{i}}=\mathbf{W}_{1}^{1}, \quad \mathrm{i}=8,9,10,11
$$

\section{VECTOR OF THE ABSOLUTE LINEAR}

VELOCITY OF THE GRAVITY CENTRE OF A BODY FROM THE MECHANICAL SYSTEM

The absolute linear velocity vector of the gravity centre $C_{i}$ of the i-th body from the mechanical system, designed in the non-moving $\mathrm{CS}$, is calculated with the equation:

$$
\begin{aligned}
& \mathbf{V}_{\mathrm{Ci}}^{0}=\frac{\mathrm{d} \mathbf{R}_{\mathrm{Ci}}^{0}}{\mathrm{dt}}=\left[\sum_{k=1}^{6}\left(\frac{\partial \mathbf{A}_{\mathrm{i}}^{0}}{\partial \mathrm{q}_{\mathrm{k}}}\right) \cdot \dot{\mathbf{q}}_{\mathrm{k}}\right] \mathbf{r}_{\mathrm{Ci}}, \\
& \mathrm{i}=1,2, \ldots, 12
\end{aligned}
$$

For every body of the kinematic model the absolute linear velocity vector is from the type:

\section{Bodies 1, 2, 12}

$$
\begin{aligned}
& \mathbf{V}_{\mathrm{C} 0 \mathrm{i}}=\frac{\partial \mathbf{R}_{\mathrm{C} 0 \mathrm{i}}}{\partial \mathrm{x}_{\mathrm{i}}} \mathbf{V}_{\mathrm{xi}}+\frac{\partial \mathbf{R}_{\mathrm{C} 0 \mathrm{i}}}{\partial \mathrm{y}_{\mathrm{i}}} \mathbf{V}_{\mathrm{yi}}+\frac{\partial \mathbf{R}_{\mathrm{C} 0 \mathrm{i}}}{\partial \mathbf{z}_{\mathrm{i}}} \mathbf{V}_{\mathrm{zi}}+ \\
& +\frac{\partial \mathbf{R}_{\mathrm{C} 0 \mathrm{i}}}{\partial \theta_{\mathrm{xi}}} \mathbf{W}_{\mathrm{xi}}+\frac{\partial \mathbf{R}_{\mathrm{C} 0 \mathrm{i}}}{\partial \theta_{\mathrm{yi}}} \mathbf{W}_{\mathrm{yi}}+\frac{\partial \mathbf{R}_{\mathrm{C} 0 \mathrm{i}}}{\partial \theta_{\mathrm{zi}}} \mathbf{W}_{\mathrm{zi}} \\
& \mathrm{i}=1,2,12
\end{aligned}
$$

\section{Bodies 3 and 5}

$$
\begin{aligned}
& \mathbf{V}_{\mathrm{Ci}}^{0}=\frac{\partial \mathbf{R}_{\mathrm{Ci}}^{0}}{\partial \mathrm{x}_{1}} \mathbf{V}_{\mathrm{X} 1}+\frac{\partial \mathbf{R}_{\mathrm{Ci}}^{0}}{\partial \mathrm{y}_{1}} \mathbf{V}_{\mathrm{Y} 1}+\frac{\partial \mathbf{R}_{\mathrm{Ci}}^{0}}{\partial \mathrm{z}_{1}} \mathbf{V}_{\mathrm{Z} 1}+ \\
& +\frac{\partial \mathbf{R}_{\mathrm{Ci}}^{0}}{\partial \theta_{\mathrm{X} 1}} \dot{\boldsymbol{\theta}}_{\mathrm{X} 1}+\frac{\partial \mathbf{R}_{\mathrm{Ci}}^{0}}{\partial \theta_{\mathrm{Y} 1}} \dot{\boldsymbol{\theta}}_{\mathrm{Y} 1}+\frac{\partial \mathbf{R}_{\mathrm{Ci}}^{0}}{\partial \theta_{\mathrm{Z} 1}} \dot{\boldsymbol{\theta}}_{\mathrm{Z} 1}+\frac{\partial \mathbf{R}_{\mathrm{Ci}}^{0}}{\partial \theta_{\mathrm{Xi}}} \dot{\boldsymbol{\theta}}_{\mathrm{Xi}}, \\
& \mathrm{i}=3,5
\end{aligned}
$$

\section{Bodies 4 and 6}

$$
\begin{aligned}
& \mathbf{V}_{\mathrm{Ci}}^{0}=\frac{\partial \mathbf{R}_{\mathrm{Ci}}^{0}}{\partial \mathrm{x}_{1}} \mathbf{V}_{\mathrm{X} 1}+\frac{\partial \mathbf{R}_{\mathrm{Ci}}^{0}}{\partial \mathrm{y}_{1}} \mathbf{V}_{\mathrm{Y} 1}+\frac{\partial \mathbf{R}_{\mathrm{Ci}}^{0}}{\partial \mathbf{z}_{1}} \mathbf{V}_{\mathrm{Z} 1}+ \\
& +\frac{\partial \mathbf{R}_{\mathrm{Ci}}^{0}}{\partial \theta_{\mathrm{X} 1}} \dot{\boldsymbol{\theta}}_{\mathrm{X} 1}+\frac{\partial \mathbf{R}_{\mathrm{Ci}}^{0}}{\partial \theta_{\mathrm{Y} 1}} \dot{\boldsymbol{\theta}}_{\mathrm{Y} 1}+\frac{\partial \mathbf{R}_{\mathrm{Ci}}^{0}}{\partial \theta_{\mathrm{Z} 1}} \dot{\boldsymbol{\theta}}_{\mathrm{Z} 1}+ \\
& +\frac{\partial \mathbf{R}_{\mathrm{Ci}}^{0}}{\partial \theta_{\mathrm{Xi}-1}} \dot{\boldsymbol{\theta}}_{\mathrm{Xi}-1}+\frac{\partial \mathbf{R}_{\mathrm{Ci}}^{0}}{\partial \theta_{\mathrm{Xi}}} \dot{\boldsymbol{\theta}}_{\mathrm{Xi}}+\frac{\partial \mathbf{R}_{\mathrm{Ci}}^{0}}{\partial \theta_{\mathrm{Yi}}} \dot{\boldsymbol{\theta}}_{\mathrm{Yi}}+\frac{\partial \mathbf{R}_{\mathrm{Ci}}^{0}}{\partial \theta_{\mathrm{Zi}}} \dot{\boldsymbol{\theta}}_{\mathrm{Zi}}, \\
& \mathrm{i}=4,6
\end{aligned}
$$

\section{Body 7}

$$
\begin{aligned}
& \mathbf{V}_{\mathrm{C} 07}=\frac{\partial \mathbf{R}_{\mathrm{C} 07}}{\partial \mathrm{x}_{1}} \mathbf{V}_{\mathrm{x} 1}+\frac{\partial \mathbf{R}_{\mathrm{C} 07}}{\partial \mathrm{y}_{1}} \mathbf{V}_{\mathrm{y} 1}+\frac{\partial \mathbf{R}_{\mathrm{C} 07}}{\partial \mathbf{z}_{1}} \mathbf{V}_{\mathrm{z} 1}+ \\
& +\frac{\partial \mathbf{R}_{\mathrm{C} 07}}{\partial \theta_{\mathrm{x} 1}} \mathbf{W}_{\mathrm{x} 1}+\frac{\partial \mathbf{R}_{\mathrm{C} 07}}{\partial \theta_{\mathrm{y} 1}} \mathbf{W}_{\mathrm{y} 1}+\frac{\partial \mathbf{R}_{\mathrm{C} 07}}{\partial \theta_{\mathrm{z} 1}} \mathbf{W}_{\mathrm{z} 1}+\frac{\partial \mathbf{R}_{\mathrm{C} 07}}{\partial \Phi_{\mathrm{y} 7}} \mathbf{W}_{\mathrm{y} 7}
\end{aligned}
$$

Bodies 8, 9, 11, 12

$$
\begin{aligned}
& \mathbf{V}_{\mathrm{C} 0 \mathrm{i}}=\frac{\partial \mathbf{R}_{\mathrm{C} 0 \mathrm{i}}}{\partial \mathrm{x}_{1}} \mathbf{V}_{\mathrm{x} 1}+\frac{\partial \mathbf{R}_{\mathrm{C} 0 \mathrm{i}}}{\partial \mathrm{y}_{1}} \mathbf{V}_{\mathrm{y} 1}+\frac{\partial \mathbf{R}_{\mathrm{C} 0 \mathrm{i}}}{\partial \mathbf{z}_{1}} \mathbf{V}_{\mathrm{z} 1}+ \\
& +\frac{\partial \mathbf{R}_{\mathrm{C} 0 \mathrm{i}}}{\partial \theta_{\mathrm{x} 1}} \mathbf{W}_{\mathrm{x} 1}+\frac{\partial \mathbf{R}_{\mathrm{C} 0 \mathrm{i}}}{\partial \theta_{\mathrm{y} 1}} \mathbf{W}_{\mathrm{y} 1}+\frac{\partial \mathbf{R}_{\mathrm{C} 0 \mathrm{i}}}{\partial \theta_{\mathrm{z} 1}} \mathbf{W}_{\mathrm{z} 1}+\frac{\partial \mathbf{R}_{\mathrm{C} 0 \mathrm{i}}}{\partial \mathbf{z}_{\mathrm{i}}} \mathrm{V}_{\mathrm{zi}} \\
& \mathrm{i}=8,9,10,11
\end{aligned}
$$

\section{CONCLUSIONS}

A kinematic model of a car with independent suspension of the front wheels and with dependent suspension of the back wheels has been created. 12 bodies are included in the kinematic model of the car. It is assumed that the bodies are perfectly rigid. The kinematic model of the car has 31 degrees of freedom.

For the gravity centre of each body from the kinematic model the absolute linear velocity vector has been derived.

For every body from the kinematic model the absolute angular velocity vector has been derived.

The absolute angular and linear velocities are used for research into the car vibrations.

\section{ACKNOWLEDGMENTS}

This material (presentation, paper, report) has been created with the financial assistance of the European Social Fund, project number BG051PO001-3.3.06-0014. The author is responsible for the content of this material, and under no circumstances can be considered as an official position of the European Union and the Ministry of Education and Science of Bulgaria

\section{REFERENCES}

[1]. Angelov Il. "Matrix Mechanics. Kinematics". Sofia, Avangard Prima, 2012, ISSN 978-954-323-917-7.

[2]. Angelov Il. "Matrix modelling in 3D space kinematics, dynamics and vibrations of mechanical modules and mass systems". Doctorate thesis. Sofia Technical University, 2001.

[3]. Angelov I., Zhelev D., Bachev V., Nikolov V. Matrix kinematics of the forklift trucks with hydrodynamical lift in the tree-dimensional space. Scientific journal "Mechanics of machines", Varna, Bulgaria, 2012, Year XX, Book 4, Issue 99, pp. 37-42, ISSN 0861-9727.

[4]. Angelov Il., Slavov V., Kabdyrakhim K., Karaivanov D. "Kinematics of Haylage Bale in 3D Space as a Body of One 
Fix Point and Two Rotations". Meccanica DOI 10.1007/s11012-013-9823-7. An International Journal of Theoretical and Applied Mechanics AIMETA, Volume 48, Number 8, 2013, ISSN 0025-6455.

[5]. Angelov Il., V. Ovcharov. "Vibration and noise in vehicles". Sofia CI "Technique" 1985.

[6]. Angelov Il., V. Bachev, V. Ahchiyski, "Matrix kinematics of the automobile in the tree-dimensional space", Bulgarian Journal for Engineering Design, issue 11, April 2012, pp. 29-38, ISSN 1313-7530.

[7]. Nikolov V. A simulation study of the controllability of a car under the influence of a sudden gust of crosswind. International virtual journal for science, technics and innovations for industry "Machines, Technologies and Materials”, Sofia, Bulgaria, 2013, Year 7, Issue 7, pp. 55-59, ISSN 1313-0226.

[8]. Slavov V. R., "Kinematics in 3d space of a mechanical unit with cylindrical and spherical joint", Bulgarian Journal of Engineering Design, broy17, January 2013, pp. 21-24, ISSN 1313-7530.

[9]. Slavov V. R., Il. Angelov, D. Kozuharov, St. Chitakov. "Kinematics in 3D space of an articulated vehicle with single-axle trailer". Technical University of Varna, Scientific journal „Mechanics of Machines” № 63, 2005, pp. 13-16, ISSN 0861-9727.

[10]. Todorov, M. D., G. Y. Vukov, A Dynamic Multiboby Model to Determine Vibrations in a Drive Train in a Wind Turbine. Proceedings of the $11^{\mathrm{TH}}$ National Congress on Theoretical and Applied Mechanics, Borovets, 2009, ISSN 1313-9665, Paper ID: 77-323-1-PB.

\section{BIOGRAPHIE}

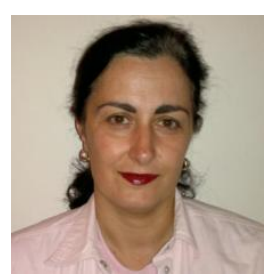

Antoniya Raydovska is postgraduate student in Department of Applied Mechanics, University of Chemical Technology and Metallurgy, Sofia, Bulgaria 